\title{
EL CORREDOR BOLIVIANO POR ARICA THE CORREDOR BOLIVIANO BY ARICA
}

Eusebio Quiroz Paz Soldán

En 1975 el gobierno chileno sometió al gobierno del Perú, de acuerdo con el protocolo anexo al tratado de 1929, una fórmula destinada a otorgar salida al mar a Bolivia por un corredor al norte de Arica. Al mismo tiempo, ya en un arreglo bilateral, el país del altiplano debía ceder a s vecino del litoral un territorio interior de extensión equivalente a la de la zona que hubiera adquirido al establecerse el corredor marítimo antedicho.

Como es sabido, la transferencia de la soberanía en cualquiera de las provincias que fueron materia del mencionado pacto 1929 - Arica o Tacna necesita la aprobación del otro estado signatario. De allí la consulta hecho al Perú. El documento que se reproduce en seguido expresa una opinión personal sobre el caso. Data de setiembre de 1976.

El tratado peruano - chileno de 1929 fue, a mi juicio, inconveniente en relación con los derechos y los intereses del Perú. Así lo he manifestado en dos libros y es innecesario repetir aquí las razones para eta opinión.

El nuevo arreglo que ahora emerge como epílogo del infortunado pacto ante dicho, no haría, ante los ojos de los peruanos desmoralizados o escépticos, sino accntuar y agravar una tendencia hacia las concesiones, que no ha sido aislada en nuestra vida diplomática.

En lo que se reficre al tratado suscrito entre Chile y Bolivia en 1904, por el cual este país aceptó la pérdida de su litoral, el escritor boliviano Jorge Escobar Cusicanqui ha dedicado varias páginas de su libro Historia Diplomática de Bolivia (La Paz, Litografías Unidas, 1975, págs., 121 130) a demostrar que nuestro vecino del Pacífico Sur lo ha incumplido en diversas formas y oportunidades.

Ocioso sería añadir aquí la larga lista de los compatriotas de esc autor que coinciden en la misma tesis.

Parece que el delegado chileno, señor Julio Philippi, manifestó que cs muy propicia la actual oportunidad para el arreglo del problema peruano chileno boliviano, gracias a la coincidencia de que los tres países tienen ahora regímenes militares. Habría agregado que existe hoy una situación similar a la de 1929, cuando gobernaban Ibáñez en Chile y Leguía en el Perú. Debe anotarse, sin embargo, que ambos jefes de Estado fueron elegidos y convivieron con cámaras legislativas. Surge entonces la pregunta acerca del significado jurídico que tiene la decisión del general Pinochet de ceder tierras de Arica.

Aquí cabe recordar la enorme intensidad de las pasiones, favorables o contrarias, que suscita la situación política chilena después de la caída y la muerte del presidente Allende y del sistema que él encabezó; y cabe también mencionar la posibilidad de una alianza ente lo que fue la Unidad Popular y la democracia Cristiana. Duda peor puede alegarse en relación con el futuro de Bolivia; quizás los reemplazantes del general Banzer acepten el corredor, pero no es seguro que se declaren enteramente satisfechos con él. En suma, este aspecto, si se quiere jurídico, legalista o formalista, merece cuidadosa atención.

Resultaría conveniente, entonces, pensar que los gobiernos de "facto" opten por el respeto a los tratados vigentes en vez de ir a la creación de situaciones nuevas en el orden internacional.

¿En qué sentido los señores Luis Undurraga y otros diputados chilenos de 1950 que se opusieron ese año a un corredor boliviano al norte de Arica sin trámites constitucionales, cuando esta fórmula fue propiciada por el Presidente González Videla, pueden coincidir con la opinión peruana de hoy?

Suponiendo que el régimen simbolizado por Pinochet cayera tarde o temprano, ¿Cuáles serían los efectos de este hecho en la política internacional de Chile y en sus relaciones con el Pcrú, totalmente alteradas? El ex - presidente Gabriel Gonzáles Videla ha recordado en sus Memorias cómo, según sus propias palabras, "sc armó la olla de grillos" por una indiscreta revelación del presidente Truman, en 1950, sobre el arreglo para otorgar a Bolivia un corredor análogo al ahora propuesto, a cambio del aprovechamicnto del agua del río Titicaca. Cuenta Gonzáles Videla que el diputado por Tarapacá, Luis Undurraga, lo acusó por

\footnotetext{
Abogado. Universidad Nacional San Agustín (Arequipa-Perú)

Correoelectrónico:percy.eguiluz@gmail.com
} 
"haber mantenido ajeno al parlamento acerca de tan importante cuestión" y por otros motivos. Agrega: "Terminaba por declararme personalmente responsable de haber propiciado la revisión de los tratados" Y dice enseguida: "En parecidos términos se expresaba el brillante diputado conservador Francisco Bulnes Sanfuentes". (Gabriel Gonzáles Videla, Memorias, Santiago, Editora Nacional Gabriela Mistral, 1975, tomo II, pág 897).

Ha habido pues antes un presidente de Chile que intentó modificar el tratado de 1929 al margen del congreso. En el caso suyo, este propósito fracasó.

\section{Las trabas en la histórica relación Tacna - Arica.}

La cancillería peruana ha hecho suya la tesis que destaca la honda relación socio-económica entre Tacna y Arica. El corredor vendría a crear un escollo porque el tráfico humano y económico entre ambas provincias quedaría sujeto a las trabas emergentes de la aparición de un tercer Estado en el área muy estrecha que separa a ambas ciudades. No está de más recordar que únicamente 57 kilómetros separa a la ciudad el puerto y que en más o menos tres cuartos de hora se viaja hoy entre ambos lugares. Cercanía que no puede ser superada.

Rota la vecindad de las antiguas provincias hermanas, habría quedado, en mi modesta opinión y no obstante la buena voluntad, decidido un punto de gran importancia que tanto Bolivia como Chile se niegan a aceptar en lo que a ellos atañe: la ruptura de una continuidad territorial. En este caso sería la ruptura en la continuidad territorial entre Tacna y Arica.

Por otra parte, en un corredor tan angosto serían muy fáciles las oportunidades para las interferencias hasta en los movimientos de los aviones y también, por la explicable tendencia del nuevo vecino para utilizar sus embarcaciones al servicio del afán de buscar y captar la riqueza pesquera. En tierra, mar y cielo surgirían así frecuentes roces internacionales.

Los juristas recordarán que con el corredor surgiría un hecho muy conocido en el Derecho Internacional, o sea la sucesión de los Estados y que solemnes documentos darán el máximo de garantías para evitar conflictos con mengua de celosas soberanías nacionales. Los eruditos libros, las elocuentes disertaciones académicas y aún los espectaculares compromisos diplomáticos, no evitarán sin embargo, lo que sin duda ocurrirá de pronto de hecho y quizá inesperadamente, en la oscura e impune realidad de cualquiera día; un policía, un inspector fronterizo, un funcionario cualquiera, negarán de hecho, por razones o pretextos impuros, la límpida doctrina, al servicios de intereses o pasiones o conveniencias o caprichos patrióticos o individuales. Del mismo modo, se ha visto innumerables veces que surgen dificultades en la frontera chileno - peruana en contra de acuerdos existentes sobre el libre tráfico. Dichas anomalías aumentarán inevitablemente como resultado de la existencia no ya de dos, sino de tres aduanas. Además, un cambio de gobierno puede conducir de modo verosímil al repudio de acuerdos suscritos por gobiernos "de facto".

Para Tacna, es evidente que un visitante chileno, por idiosincrasia y costumbres, equivale, por lo menos a un promedio de tres bolivianos en lo que se refiere al "consumo". Cuando las relaciones entre el Perú y Chile sean auténticamente normales, podría ser estimulado y desarrollado el movimiento turístico de frontera que vincule a Tacna por intermedio de Arica, con gentes del Sur de Chile y de Argentina.

\section{No remachemos la mediterraneidad de Tacna.}

Dese 1929 vive Tacna bajo el riesgo de su eventual asilamiento. Previeron lo que podría sobrevenir de esta situación los señores Hernán Velarde, Alberto Salomón y Wade Ellis cuando una de sus conferencias con el Secretario de Estado Frank Kellogg, la de 6 de octubre de 1926, le informaron que "sin el ferrocarril y sin Arica, Tacna quedará encerrada, asilada de su comunicación con Bolivia y dependiendo para su comunicación marítima de las facilidades que el poseedor de Arica quisiera proporcionarle". (Nota de Velarde al Ministerio de Relaciones Exteriores de Lima, 6 de octubre del 1926, en el archivo del Ingeniero Héctor Velarde, cit. en J. Basadre, La Vida y la Historia, Lima, primera educación, Banco Industrial del Perú, 1976, pág 324). El diplomático chileno Mario Barrios en su libro Historia Diplomática de Chile, (Barcelona, Ediciones, Ariel, 1970, pág. 710) al aludir a las primeras conversaciones en Lima en torno a lo que fue más tarde el tratado de 1929, basadas según él afirma, en un previo convenio confidencial entre los embajadores de Perú y Chile en Washigton, menciona lo siguiente: " 1 () Trazo de una línea de frontera entre Tacna y Arica; $2^{\circ}$ ) Estudio de una zona comercial franca que impidiera la asfixia de Tacna”... etc.

"iLa asfixia de Tacna!". Esta frase del chileno Mario Barrios señala un peligro y marca un programa que el Perú tiene el deber de no olvidar jamás.

La fórmula Banzer-Pinochet, a los cuarenta y siete años del tratado Rada y Gamio - Figueroa Larraín, abre un nuevo interrogante en relación con la asfixia de Tacna. Y aquí resulta oportuno repetir que a Tacna le conviene; por múltiples motivos, seguir teniendo dos fronteras: con Chile y Con Bolivia.

No cabe negar que, en relación con este último país, en los actuales momentos, existe una buena 
cantidad de obstáculos para el normal funcionamiento en una vecindad que es la histórica, la obvia, la sancionada por una existencia multisecular. Dichas trabas ya tuvieron un punto de partida en la construcción del ferrocarril a la Paz. (1904-1913), previsoramente orientado para evitar el acceso al altiplano señalado a través de los siglos por el arrieraje desde Tacna; una de sus etapas ulteriores estuvo en el contenido del protocolo anexo al tratado de 1929 que prohibió en nuestro departamento la eventualidad de nuevas vías férreas internacionales. Es obvio que no existe hoy un tráfico intenso tacneño-boliviano y que, como se verá a continuación, acabase de tomar medidas para obstaculizarlo aún más, si bien hay ferias o conatos de ferias y otras evidencias comprobatorias de que no ha muerto. De todos modos, tarde o temprano llegará la integración que el "tiempo largo", del provenir anuncia, impertérrito, no obstante la voluntad de gobiernos fugaces y facilitará las dos saludables corrientes de intercambio. Reducirlas a una sola puede implicar o no una solución a la mediterraneidad de Bolivia; pero ayudará a remachar la mediterraneidad de Tacna.

El comercio de nuestra ciudad, abierto y sin trabas muy difíciles hacia el Pacífico en caso de que no se interponga un tercer Estado, estará en capacidad de llegar, a la vez, hasta el Atlántico.

\section{El comercio Arica - Tacna - Bolivia}

El corredor estará, repetimos, demasiado cerca de la provincial parcialmente recuperada por nosotros en 1929, tan cerca que ha de tener incalculables y quizás revolucionarias repercusiones demográficas, culturales y económicas (estas últimas, ligadas, sin duda al contrabando). Entre otras cosas, liquidará o erosionará los contactos Arica - Tacna. Bolivia. Vale la pena recalcar que aquí se alude a una línea completa, del mar al altiplano. Digan lo que digan informantes oficiales, cuyo testimonio no ha sido contrapesado con el de los protagonistas en este asunto, dicho comercio se ha hecho no obstante la horrible realidad de la carretera del Desaguadero. Algo más, puede y debe ser estimulado, aunque muy recientes dispositivos prácticamente lo cortaron. Según algunos, los camiones en el mencionado tráfico malograban la carretera que, sin embargo, está preparada para resistir tanques.

Afírmase, asimismo, que nada gastaban los camioneros en Tacna, si bien ellos, en su trajín cotidiano, dejaban o podían dejar dinero, inevitablemente; por ejemplo, cuando compraban cigarrillos, alimentos u otros artículos o cuando se les malograba alguna pieza. Se sospecha que detrás de estos transportistas había una máscara del espionaje.
A los servicios de Inteligencia les es más fácil utilizar a presuntos turistas o a otros visitantes de la ciudad, menos apresurados, sin perjuicio de que agentes peruanos acompañen o vigilen todo este movimiento. Se habla de la diferencia entre el alto precio de la gasolina chilena y el bajo precio de la gasolina peruana, que podía ser utilizada en daño nuestros; sin embargo, pronto ha de subir el precio a este lado de la frontera y, además, sería fácil racionar en este caso el volumen de los suministros. Los comerciantes que utilicen la vía Arica - Tacna - Bolivia cuando cesen las inconvenientes trabas actuales o cuando el camino mejore, han de ser propagandistas a favor de movimiento de personas o mercaderías en la zona. He tenido en mi poder la tarjetas de un próspero comerciando te de Santa Cruz de la Sierra, o de origen árabe, vivamente interesado en utilizar la ruta de Tacna para el traslado de sus envíos de azúcar al mar.

Aquí resulta oportuno insistir en la conveniencia de que no se posponga o margine la ruta Tacna - Bolivia. Un rumor generalizado atribuye esa negligencia voluntaria a razones de estrategia. Tomándolas en cuenta en todo lo que valen, conviene señalar que el enlace Tacna - La Paz no haría sino revivir tradicionales vinculaciones que ya la Cámara de Comercio de nuestra ciudad se encargó de señalar en un folleto merecedor de atenta lectura (Anexo C: Realidad histórica y perspectiva del desarrollo de Tacna en función de la carretera a la Paz. Tacna, Tipografía Santa María marzo 1973).

\section{¿Depende la paz autentica y durable de un mágico pedazo de papel?}

He oído decir a un intelectual amigo muy estimado en Lima que es partidario de la fórmula boliviano-chilena, pues gracias a la magia de ella se colocará una cuña o barrera entre los dos grandes adversarios de 1879, quedará cortado el armamentismo y vendrá la paz. Leamos el libro de Pinochet, pesemos bien la tesis de Ritter, que serán mencionados en seguida y llegaremos a la conclusión de que el corredor no es garantía de paz permanente, digan lo que digan tratados cuya celosa observancia en el transcurso de los años futuros nada puede garantizar.

Aquí me permito mencionar dos obras fundamentales del Siglo XX: la de Raymond Aron Paix et guerre entre les nations (París, Calmann-Lévy, 1962) y la de Pierre Renouvin y J.B. Duroselle Introduction á l'histoire des relations internationales (París, A. Colin, 1964). Aron hace un conjunto de reflexiones que giran sistemáticamente alrededor de un análisis racional basado en temas y en conceptos suministrados por la filosofía, la sociología y la historia en torno a la teoría 
de las relaciones internacionales. El suyo está lejos de ser un planteamiento puramente abstracto, evasivo ante las conclusiones prácticas; hallase ubicado también lejos del empirismo que, inmerso sólo en los hechos y únicamente a ellos atendido, se limita a hacer de la teoría una contemplación falsamente "desinteresada" (en realidad, momificada)

Con una vasta información sobre teorías, conocimiento y normas, Aron llega a conclusiones orientadas hacia la definición de una ciencia de la guerra y de la paz. Renouvin y Duroselle, por su parte, intentan determinar los móviles generales de la política exterior de los estados modernos y señalar los mecanismos envueltos en ella mediante el empleo del método histórico como instrumento de trabajo.

¿En qué sentido ambas atribuciones pueden ser útiles aquí? Naturalmente, ellas operan en un campo muy vasto, ajeno a este mundo mundillo latinoamericano. Sin embargo, dentro de nuestros provincianismo relativo, vivimos en este continente también bajo el imperio de distintos estados que son unidades de decisión política, inmersos al mismo tiempo, en contradicciones internas y sujetos a los marcos ineludibles de la vida contemporánea. Quienes somos ciudadanos de cualquiera de estos Estados, resultados, de una manera u otra, "homus politicus". Un arreglo diplomático, sobre todo, en el Perú, cuando se trata de una cuestión de tanta trascendencia histórica como el problema del sur, nos afectará evidentemente. De aquí que debemos estar muy atentos ha dicho arreglo. Ello quiere decir, en verdad que no debemos juzgarlo con un inconsistente criterio, de antemano complacido con las apariencias las ciegas pasiones que originan bruscas y violentas locuras o monstruosidades en la vida de los pueblos no son, por cierto, aconsejables; pero tampoco lo son los juicios precipitados, gratuitos y, en realidad frívolos. Aquí cabe aplicar dos conceptos que J.B. Duroselle utiliza: de un lado la "estrategia diplomática", o sea la relación entre el valor de aquello que se concertó o trata de concertar y el nivel del riesgo a él inherente; y por otra parte, la "táctica diplomática" o sea la relación entra la verdadera finalidad perseguida y los medios prácticos utilizados para afrontarla. Como "estrategia diplomática" la solución de la mediterraneidad Boliviana y el enfriamiento en las tensiones latentes o probables entre el Perú y Chile tiene que parecer, ante mucha gente, deseable. Sin embargo, lo más importante es indagar si aquí la "Táctica diplomática" resulta, dentro de su campo espacial y temporal específico, autentica o eficaz o, por el contrario, si oculta, en el fondo, trampas y "bombas de tiempo". La lógica implícita entre las colectividades políticamente organizadas debe buscar objetivos razonables, o sea escoger, dentro de los límites de los calculable, aquello que es sanamente realizable. la racionalidad (alguien ha empleado el neologismos "razonabilidad") en la acción político-diplomática deberá tomar como meta una búsqueda de seguridad, de confianza, de efectividad fecunda en sus realizaciones. La paz tiene su tipología. La paz, cualquier paz, no es una ideal en sí. Existen la paz provisional o de la espera, la paz de la hegemonía, la paz del imperio, la paz del poder, la paz de la sujeción, la paz falsa y precaria tras de la cual se enmarcaran propósitos de agresión. Ninguna de ellas es apetecible. La última de ellas, la más siniestra, es, al mismo tiempo la más aviesa. Solo es satisfactoria la paz de justicia y de estabilidad. A esa paz no iba la formula Banzer-Pinochet.

\section{El argumento Pinochet sobre la fácil movilidad de los corredores marítimos estrechos $y$ el argumento Ritter sobre la necesidad de los litorales amplios.}

No voy a insistir en lo que significa, en función del porvenir, la tesis sostenida por el general Augusto Pinochet en su libro sobre Geopolítica, en relación con los países que obtiene una muy angosta faja de litoral entre otros dos estados e inevitablemente tratan de ampliarla. Como prueba de la inevitable tendencia que surgirá entre los bolivianos para ensanchar su salida al mar no hacia el sur, donde tropezarían con el casco de la ciudad de Arica, sino hacia el norte, está lo expresado por el publicista señor Federico Nielsen Reyes (hasta hace poco partidario de la salida al mar de su país por Pisagua) en uno de sus viajes a Lima, sin duda alguna, sin haber leído a Pinochet: los peruanos tendremos, tarde o temprano, que resignarnos a ser empujados hacia el norte en la costa, precisamente (me permito agregar) dentro del área en que es más grande la riqueza pesquera.

Cuando escribió su libro y cuando, años más tarde, formulo su propuesta, sin duda, el general Pinochet conoció la doctrina de Karl Ritter (17791894), profesor de Geografía en la Universidad de Berlin, a quien Valerie Fifer cita en su libro Bolivia: Land, Location and Policies since 1825, Canbridge University Pres 1972, pág 251. Según Ritter, tan sólo un litoral extenso, es decir proporcionalmente vasto en relación con las áreas del interior, puede tener una efectiva significación en el desarrollo de un estado víctima del atraso. La accesibilidad marítima, siempre y cuando sea considerable, dará los requisitos necesarios para el verdadero florecimiento del comercio, la inmigración y otros avances. Sin saberlo, recogió el pensamiento de Ritter la Misión chileno de don Emilio Bello Codesido que, en el Acta protocolizada del 10 de enero de 1920 , dejó establecido que su país estaba dispuesto a procurar un corredor 


\section{La Vida y la Histaria}

Quiroz, E. El Corredor Boliviano por Arica

para Bolivia al Norte de Arica y del ferrocarril a La paz, pero con una amplitud que llegaba hasta el río Sama. La Profesora de Geografía de la Universidad de Londres, a la que acabo de mencionar, recuerda este episodio en la pág. 33 de la obra citada. Sin el angosto corredor Banzer-Pinochet se convierte en una realidad, el riesgo invívitu en la propuesta de la misión BelloCodesido aparecerá inexorablemente en el provenir como un tentador fantasma.

\section{La aridez del corredor y sus peligros}

El corredor estaría ubicado en una zona muy árida. Necesitará agua, mucha agua. ¿De Dónde ha de provenir ella? Los bolivianos pueden prometer al Perú la entrega del contenido de la Laguna Blanca o de los deshielos que salen del nevado Tacora, o el mejoramiento de los canales cuya servidumbre pasaría a su poder o la irrigación mediante el uso del Río Maure. De hecho, sin embargo, en el sector alto del territorio que ellos adquirirían, con este gobierno u otro posterior, por razones humanas muy fáciles de comprender, harán todo lo posible y utilizando todos los medios, por obtener agua e cualquier modo y este empeño ha de chocar con los intereses de Tacna, vitalmente unidos a la necesidad de, por lo menos, conservar intactos todos sus actuales recursos hídricos. Con Chile, que está ahora en poder de la zona, no han surgido problemas en esta servidumbre de paso, ya que ha contado con los recursos de Azapa y luego con el Lauca.

En el territorio cercano al mar, procurarán nuestros presuntos vecinos captar la napa acuífera del subsuelo y ellos redundará en perjuicio de la agricultura actual o futura del a pampa Los Palos, zona cerca de La Yarada, que fue reincorporada a la producción sólo desde los años 1950, más o menos, por los esfuerzos de Josúe Grande, inversionista de millones en esta original irrigación mediante pozos en los que hoy depositan capital o trabajo muchos productores de una nueva riqueza que, entre sus variantes, ofrece la propagación de acciteras capaces de llegar a ser las más importantes del Perú. La tierra saturada de agua oculta en la totalidad del área aquí mencionada, no está aun íntegramente explotada por los peruanos. Los nuevos ocupantes del presunto corredor en la parte cercana al litoral, disminuirán los recursos que los agricultores peruanos de Los Palos han de hallar. Habrá quienes refuten esta afirmación diciendo que también los chilenos pueden irrigar dicho sector y que para ello tienen derecho. No sería lo mismo, sin embargo, lo que ellos hagan y lo que provenga de quienes recién llegados, angustiosamente necesitarían crear de la nada una población y darle de inmediato los recursos necesarios para su existencia día a día.

\section{¿Son las aguas del Maure las únicas que pueden enriquecer la agricultura de Tacna?}

Puede ser que algunos se sientan inclinados a apoyar el corredor si Bolivia cede las aguas del Maure que, según diversos testimonios, refrendados por el geólogo señor Mario Vásquez Moreno y por otros testimonios muy respetables, son las únicas que pueden enriquecer la agricultura de Tacna.

Para tratar del vital asunto relacionado con los recursos hídricos de este departamento, reproduzco a continuación algunos párrafos de un documento que ha sido aprobado por el Colegio de Ingenieros de la ciudad. Dice así:

Recursos Hidricos potenciales que se deben traer a Tacna para conseguir el desarrollo económico y social

Como se puede apreciar actualmente, Tacna sin agua abundante no puede intentar dar un paso más adelante, sin correr el riesgo de tomarse toda el agua para la ciudad y secar sus campos agrícolas. El agua abundante existe en la cordillera la cuenca del Titicaca y sólo hace falta la mano del hombre patriota y decidido para desviarla hacia nuestras tierras y convertirnos en el más grande centro productor de alimentos.

Los principales recursos de agua que tenemos y que son materia del pedido que hacemos al señor Presidente de la Republica General de División E.OP. Francisco Morales Bermúdez son los siguientes:

Aguas subterráneas del estrato Capelluni Estudiado por la S.P.C.C. es posible esperar bombear: $3 \mathrm{~m}^{3}$

\section{Aguas del sistema Maure integrado por cuencas}

Es posible obtener por gravedad y por bombeo, según estudios realizados por el MITSUI y E.P.D.C.: $9 \mathrm{~m}^{3}$

\section{Aguas de la cuenca del rio llave}

Superficiales, derivadas por bombeo, constituyen la más importante reserva hídrica para Tacna: $20 \mathrm{~m}^{3}$

El total de estas aguas hacen $32 \mathrm{~m}^{3}$ que están acondicionadas para su derivación más fácil al bombeo hidroeléctrico, con el fluido que generan las propias aguas en su gran desnivel hacia la cuenca del Pacífico, contando ya Tacna con centrales de arranque instaladas $\mathrm{y}$ funcionando en Aricota con 35,000 kw. 
La vertiente del Pacífico del departamento de Tacna tiene tres cuencas que por la proximidad de la Cordillera Occidental al mar, son relativamente chicas y descargan muy poca agua con la que supervive Tacna. Tacna tiene sólo tres cuencas de recepción que formar otros tantos valles, que inicial en la sierra y bajan a la costa y tiene una pequeña irrigación con la desviación del río Uchusuma de la vertiente del Titicaca y otra irrigación también pequeña con aguas subterráneas en la pampa de La Yarada. Las descargas de estas cuencas son:

Cuencas del río Locumba

Para dar la información más visual presentamos el diagrama que sigue:

$\begin{array}{lll}\text { Cuenca } & \text { Descarga } & \text { Riego } \\ 2,400 \mathrm{~km}^{2} & 2 \mathrm{~m}^{3} & 6,000 \text { Has. }\end{array}$

$\begin{array}{lcc} & \text { Cuencas del río Sama } \\ \text { Cuenca } & \text { Descarga } & \text { Riego } \\ 2,600 \mathrm{~km}^{2} & 2 \mathrm{~m}^{3} & 8,000 \text { Has. }\end{array}$

Cuencas del río Caplina

El río Caplina con su mísera descargar riega el valle del Caplina y sostiene la ciudad de Tacna.

$\begin{array}{lll}\text { Cuenca } & \text { Descarga } & \text { Riego } \\ 532 \mathrm{~km}^{2} & 0.55 \mathrm{~m}^{3} & 1,200 \text { Has. }\end{array}$

Cuencas del río Uchusuma

Río de la vertiente del Titicaca, fue desviado a Tacna por el año 1875 y completado al revestimiento del canal en el gobierno del general Odría.

$\begin{array}{lcc}\text { Cuenca } & \text { Descarga } & \text { Riego } \\ 477 \mathrm{~km}^{2} & 0.4 \mathrm{~m}^{3} & 1,300 \mathrm{Has} .\end{array}$

\section{Aguas subterráneas en La Yarada}

Funcionan aproximadamente 60 pozos accionados con energía eléctrica que se sostiene por la tarifa especial que se paga:
Cuenca Descarga.
Riego
Desconocida $1 \mathrm{~m}^{3}$
2,000 Has,

En suma la miseria de $5.95 \mathrm{~m}^{3}$ que arroja toda la vertiente del Pacifico, sumando todavía el Uchusuma y las aguas subterráneas de La Yarada se sostienen alrededor de 18.500 Has de cultivo en todo el departamento de Tacna considerando sus partes de sierra y costa, más todos los centros poblados incluyendo la ciudad de Tacna, capital del departamento.
Existen pérdidas de aguas por filtración en los canales en funcionamiento, que se pueden recuperar con la reparación de los mismos, así como pequeñas reservas que por desagüe de las lagunas, pequeños reservorios, drenaje, etc. Pueden aportar $1 \mathrm{~m}^{3}$ en total, que servirán para mejorar en algo el paupérrimo abastecimiento de agua actual, pero que de ninguna manera constituyen la solución del problema del desarrollo económico y social de Tacna, que reclamamos con todo el patriotismo que se merece Tacna, por ser la frontera sur. Los pequeños recursos a que aludimos son los siguientes:

\section{Reparación del canal de derivación del Uchusuma}

Reparación total y conservación permanente del canal revestido, de derivación del río Uchusuma en la cordillera que sobre los $0.4 \mathrm{mt}^{3}$ del promedio del estiaje que aporta actualmente, se puede recuperar $0.150 \mathrm{~m}^{3}$ permitiendo llegar a Tacna unos $0.550 \mathrm{~m}^{3} \mathrm{en}$ los meses más difíciles.

\section{Terminación de la represa de Paucarani}

En los orígenes del río Uchusuma, existe una construcción una pequeña represa de almacenamiento iniciada en 1964 y paralizada por la falta de estudios geológicos, que puede almacenar las aguas de todo el periodo de lluvias del 15 de diciembre al 15 de marzo y las aguas de los meses de junio y julio que discurren en su vaso de recepción almacenando unos 5 millones de $\mathrm{m}^{3}$ que pueden aportar unos $0.180 \mathrm{~m}^{3}$ en forma permanente.

\section{Desagüe de la laguna Casiri}

Esta laguna está situada cerca de la represa de Condorpico con un espejo de agua de 150 Has a una altura de 5,000 mts., tiene estudio preliminar ejecutado por la EPDC y por la COFDET, que estima que construyendo una compuerta de regulación de desagüe se puede obtener un gasto permanente de 0.160 $\mathrm{m}^{3} / \mathrm{seg}$.

\section{Planta de bombeo en Patapujo}

Existe el estudio terminado de ésta, que puede bombear al canal de Uchusuma con motor a petróleo de $0.100 \mathrm{~m}^{3}$ (aprox.)

\section{Bombeo de los bofedales de Laguna Blanca}

Laguna Blanca es un interesante 


\section{La Vida y la Historia}

Quiroz, E. El Corredor Boliviano por Arica

reservorio que tiene aguas que discurren lentamente hacia el este. Estudios elaborados por EPDC en el Plan Tacna calculan obtener $0.200 \mathrm{~m}^{3}$ que tienen que ser bombeados al Canal del Uchusuma, ejecutando trabajado de desagüe, estanque y planta de bombeo.

\section{Bombeo de agua del subsuelo en la cabecera de la ciudad de Tacna.}

Los estudios de sondaje y resistividad eléctrica ejecutados por encargo de la COFDET por el Ing. José Arce Helberg en1968, indican ocho puntos favorables para perforación de pozos. En la cabecera de la ciudad de Tacna perforaron dos pozos y se equipó uno que descarga $0.030 \mathrm{~m}^{3}$. Si se perforan y se equipan los otros puntos y esperando tener un rendimiento mínimo igual a la nuestra se podría bombear $0.210 \mathrm{~m}^{3}$.

Ejecutando todos estos pequeños trabajos que pueden ser realizados dentro de los programas anuales de la Zona Agraria VII del Ministerio de Agricultura, se puede aumentar un caudal de $1 \mathrm{~m}^{3}$ más, que servirá sólo para regularizar el riego del valle del Caplina y las irrigaciones del Uchusuma y Magollo deficitarias en agua para sus actuales áreas. Siendo necesario ejecutarlas, no constituyen base del despegue para el desarrollo económico y social que ansía Tacna para estar en igualdad con sus hermanas provincias del norte del País.

Conviene recordar, en suma y sin entrar en más pormenores, que no se ha utilizado todavía íntegramente el potencial de aguas que pueden ser llevadas a Tacna.

Hasta aquí el informe sobre recursos hídricos de Tacna, aprobado por el Colegio de Ingenieros de esa ciudad en mayo de 1976.

La empresa Southern después de un estudio de sus técnicos, llamado "Proyecto Capelluni", hállase segura de haber encontrado un estrato acuífero subterráneo llamado "Capelluni" en la cordillera occidental, del que proviene el líquido elemento para el desarrollo minero de ese territorio. Obtienen un promedio de 100 a 300 litros por segundo cuando lo requiera. Se ha sugerido que este mismo estrato puede prologarse hasta la cordillera de Tacna. Sin embargo, hay técnicos del Ministerio de Agricultura que descarta tal posibilidad; parece que no han sido hechos sondeos con pozos tubulares de estudio.

Sería muy conveniente que haya al respecto una investigación con una máxima dosis de seriedad, si es posible con ayuda de los mismos especialistas de la
Southern. Sea lo que fuere, no faltan quienes piensan que ésta sería un agua muy cara por cuando implicaría un permanente gasto de bombeo; el mantenimiento no podría sopórtalo fácilmente la agricultura. El desarrollo auto sostenido que la región necesita (afirman estos escépticos) solo se pude hacer con agua. que discurre por la superficie, hecho susceptible de facilitar un evaluación de su volumen y la permanencia de disponibilidad. La minería y la industria en grande (terminan ellos diciendo) si pueden pagar una irrigación de alto costo como al que esta la Southern para Cuajone. En resumen (vale la pena insistir en ello) se necesita aquí un estudio minucioso y con todas las garantías de seriedad máxima.

En la zona de Sama y Locumba está la amplísima pampa Cabeza de Vaca. Acerca de la posibilidad aquí existente, me informa privadamente un técnico tacneño:

"Cabeza de Vaca es una zona que si se puede desarrollar y que se tienen que realizar forzosamente cuando se utilicen toda su capacidad las dos centrales hidroeléctricas de Aricota que tienen una capacidad instalada de $35,000 \mathrm{kw}$ para un gasto de agua de 4 metros cúbicos por segundo. Actualmente se estarán usando algo menos de $1.5 \mathrm{~m}^{3}$, con los cuales se abastece regularmente el valle de Locumba y la irrigación de Ite que ahora dispone de una dotación de riego suficiente. Pero cuando las dos plantas trabajen en toda su capacidad debe sobrar agua de bombeo de Aricota para irrigar unas 500 a 1,000 Has. en las pampas de Cabeza de Vaca, siempre y cuando además la laguna de Aricota fuera integrada a régimen permanente; lo que significa derivar hacia de la otros recursos hídricos de la cordillera para que su nivel no baje. Si esto no se hiciera y se dejara tal como la proyectaron los japoneses para que sus centrales hidroeléctricas funcionaran como centrales de punta cuando funcionaran las centrales proyectadas con la derivación del río Maure, el agua disponible sólo duraría alrededor de quince a veinte años, siendo un periodo precario para un plan agrícola".

El mismo concienzudo informante dice a continuación lo siguiente, a propósito del río Ilave:

"Es la solución para Tacna por el volumen de agua que se puede traer. Existen estudios preliminares en los Planes Regionales del Sur que efectuará el Ing. Rosendo Chávez Díaz; a este respecto puedo decirle que falta en el alto nivel ordenar efectuar el estudio definitivo de este recurso en el que sólo se tiene 
que buscar la alternativa de la ruta que traería para llegar al valle de Tacna. No caben estudios preliminares ni estudios de factibilidad económica que es por donde nos marean la perdiz los técnicos del gobierno por la incapacidad de operación que tiene el Estado. El estudio hay que encargarlo a una empresa especializada extranjera o de una institución financiera llámese BID o Banco Mundial, etc. En estos momentos en que en todo el mundo es necesario impulsar la producción agropecuaria, lo único que se tiene que estudiar técnicamente es por donde resulta más fácil traer el agua, sin medir su costo, porque lo que el agua va a producir paga cualquier inversión. Para hablar de valores actuales a groso modo le calculamos una inversión aproximada de los $30 \mathrm{mil}$ millones de soles para traer unos $20 \mathrm{~m}^{3}$ de agua. Este valor tuve la oportunidad de planteárselo al Ministro de Economía el Dr. Barúa en el almuerzo de Pachía el 28 de agosto cuando estuvo en esta el Presidente Don Francisco. Me dijo que era cifra mayor y que requería inversión extranjera. Le dije que por lo que conocía, ninguna irrigación del país se había hecho o se estaba ejecutando con recursos propios del país; me indicó que en la delegación que visitaba Tacna, en esa oportunidad había un representante del BID y que iba a ver qué podían hacer ellos por este proyecto. Desgraciadamente los tacneños sólo nos novemos el 28 de agosto y después dejamos pasar el tiempo los 360 días del año. Si el gobierno tomara la decisión de ejecutar la derivación del Ilave, tendrá que disponer la ejecución estudio definitivo del proyecto. Por ahora nos han tapado la boca con el estudio integral de cuencas delos departamentos de Tacna y Moquegua que, al paso que van, consumirán unos cuatro años y las obras si algún día se ejecutan será el próximo siglo. Si se requiere realizar obra verdadera y se dan las órdenes precisas, el estudio puede demorar un año y los trabajos cuatro años. El Ilave podría estar en Tacna para el año 1981. No es posible que en las esferas de todos los últimos gobiernos nos hagan sentir el temor de invertir en Tacna y se percibe que la frontera económica de la patria está reflejada hacia Arequipa. Es Tacna a la que hay que pintarla de verde, es el valle de Tacna en el que hay que efectuar la ocupación territorial mediante la implantación de irrigación para enraizar y afianzar a la gente trabajadora y patriota de esta bastión de la patria”.

\section{La no despreciable realidad del "tráfico hormiga"}

Se aduce, con cifras estadísticas a la vista que el tráfico mercantil entre Tacna y Arica es ahora ínfimo, si bien no se niega que hay un incesante movimiento humano entre ambas ciudades. Es evidente que hay negativos efectos ocasionados por la no construcción del muelle peruano en dicho puerto y por la visible tendencia oficial de disminuir los contactos con él. Además en la actualidad existen dificultades notorias por la escasez de divisas, o por haber monopolizado el Estado la mayor parte de la comercialización de los productos típicos de exportación chilena (frutas secas, menestras, conservas de fruta, etc.). Sin embargo, personas serias me acaban de informar (agosto y setiembre de 1976) que últimamente ha crecido el volumen del envío de pescado de Arica o del sur de Arica, en parte a través de las llamadas empresas de pesca artesanal, al frigorífico de Tacna. Nadie puede negar, además las filtraciones emanadas de las diarias tareas de las "pacotilleras". Las hemos visto hacinadas oprobiosamente, como si no fueran seres humanos, en Tacna, en los pobrísimos vagones el ferrocarril que administra ENAFER PERU; o dando un espectáculo lamentable a las puertas de la no menos miserable estación de dicha vía en Arica, como si se quisiera exhibir así nuestra presencia en el puerto Bolognesi; o en los camiones y autobuses que trafican por la carretera. Pero todos sabemos también que cruzan por los cerros y que a través de esta incógnita vía, han transportado, en más de una oportunidad y en la noche, pesadísimos objetivos sin ayuda de ningún vehículo. Expresión típica del sub desarrollo y del sub empleo que ocho años de revolución no han disminuido, las o los "pacotilleros", forman los grupos más privilegiados en los 14 pueblos jóvenes de Tacna, con sus 37,000 habitantes según cálculos aproximados. Las construcciones en esos "pueblos jóvenes" son de material mucho más noble que el de los asientos similares en Lima. Cálculos oficiales, probablemente incompletos afirman que diariamente viajaban entre Tacna y Arica unas 70 a 80 "pacotilleras".

Está difundida la tendencia a considerar que este comercio hecho por gentes llamadas "hormigas" abarca sólo especies de ínfima calidad. Grave error. Una valorización de todo lo que se veden en el llamado "mercadillo" de Tacna dará una suma muy considerable. He encontrado allí, por ejemplo, a pesar de las normas oficiales, mantequilla holandesa traída de Arica, una gran variedad de vino y licores, fideos, fruta fresca, seca o en conserva, golosinas, menestras, 


\section{La Vida y la Fistoria}

Quiroz, E. El Corredor Boliviano por Arica

perfumes, productos relacionados con la belleza femenina, radios, tocadiscos, cigarrillos de diversas marcas, ropa interior y muchas otras cosas. También es fácil ver importaciones bolivianas, brasileras, argentinas y de otras partes. No faltan, justo es agregar mercaderías peruanas. Surge fácilmente la idea de que si convenios eficaces recogieran la realidad de este mundo semi-clandestino, saldríamos ganando todos. Hay un "corsi" y "ricorsi" en el enlace con Arica. Ahora, la tendencia es que más chilenos viajen del puerto a la ciudad. Los he visto vendiendo pública, osadamente, vinos, frutas, etc. Hasta setiembre de 1973, el movimiento fue en sentido inverso. Acuerdos explícitos, circunstancias favorables, pueden y deben evitar incidentes, facilitar una circulación que, no obstante los más diversos obstáculos, resulta inexorable aunque, en determinados momentos aparezca restringida forzadamente.

\section{¿Cuál será de inmediato el verdadero puerto de Bolivia?}

Se ha repetido mucho que habrán dificultades económicas y técnicas para construir de inmediato un puerto y crear de la nada una infraestructura humana en el angosto paraje que Bolivia obtendría al norte de Arica.

Existe la fundad sospecha de que nuestro aliada de 1879 se contenta, por ahora, mientras pasa del proyecto a la realidad ese milagro, con llegar simbólicamente al océano y con lograr un acercamiento indiscutible al puerto cuyos profesos llame de "vitrina" nuestro Instituto Nacional de Planificación, sin recordar que en ese lugar está clave para buena parte del comercio con el antiguo Alto Perú y para la llegada inevitable el Brasil a la zona del Pacifico. No fucron razones frívolas las que impulsaron a Chile a hacer en Arica inversiones anuales veinte veces mayores que las que se hacían en Tacna; a desarrollar un puerto con capacidad de dos millones de toneladas al año; y a darle un impulso industrial cuya significación se mide por el hecho de que al caer el régimen de la Unidad Popular, la municipalidad estaba presidida por una alcaldesa comunista. Impulso notable que tuvo, entre otras facetas, la agresión cultural simbolizada por tres universidades y una espléndida estación de televisión.

En otras palabras, Arica se beneficiará una vez más ahora con la inmediata vecindad de Bolivia. Si ello ocurre, ¿para qué el muelle peruano? No habrá muchos barcos que atraquen en él, después de acoderarse en todos los muelles de aquel pucrto, ampliamente entregados al comercio boliviano. ¿Qué garantías seguras en función, no sólo del presente sino del futuro, ofrece la nueva situación para el Perú y especialmente para Tacna?
De otro lado, la sola noticia de que van aparecer asentamientos en el territorio del corredor, atraerá un flujo de población aventurera salida de Tacna o de otros lugares del Perú, con efectos dañinos para nosotros en el orden material o moral. No se olvide que en Bolivia hoy circulan dólares sin dificultades y ese atractivo ejercerá, junto con otros, evidente influencia.

\section{El recuerdo de los libertadores como coartada para hacer ahora sacrificios}

No faltan quienes dicen que es necesario invocar, para el problema ahora planteado, el legado americanista de los libertadores. Por cierto, el único país situado en el caso de otorgar concesiones fundamentales sería el Perú, ya que Bolivia obtendría su salida al mar por una faja de territorio ininterrumpida y las ventajas para Chile resultarían obvias gracias a la adquisición de tierras altiplánicas, Hermanarnos, olvidar las llagas del pasado: ¡idílica ilusión! Pero la feroz realidad de hoy exhibe la vigencia de un pacifismo con negras intenciones: el de los imperialismos, los estados expansionistas en el Pacífico y en el Atlántico, las empresas transnacionales, la sociedad de consumo, las fuerzas económicas sin ideales. Los predicadores de la fraternidad Latinoamérica se adelanta, cuando las condiciones no son favorables, nadie sabe por cuánto tiempo, a la verdadera transformación del continente que será redimido en el futuro, si es que el milagro se realiza.

No creo que, dentro del proceso de la historia, cabe hablar de "Chile" "Perú" o "Bolivia" como personas colectivas inmutables. Estos países y todos los demás han sido y son dirigidos por clases, grupos, sectores o figuras rectoras que pueden no ser iguales a través del tiempo. Sabido es que, en el caso de Chile, Bernardo O'Higgins se opuso a los designios de Portales contra la Confederación Perú - Boliviana. La oligarquía político - financiera que, estrechamente ligada a los capitales británicos beneficiarios en las salitreras de Antofagasta y vivamente interesados en las de Tarapacá, provocaron la agresión y la conquista de 1879 , recibió la crítica franca de hombres integérrimos como Juan Enrique Lagarrigue, Carlos Vicuña Fuentes y otros chilenos; y, en nuestros días, de historiadores heterodoxos como Luis Vítale. Por desgracia, Chile no está gobernado hoy por herederos o sucesores o congéneres de esos verdaderos americanos. No lo olvidemos.

En las horas fugaces, se vislumbró antaño, débilmente, otro tipo de relaciones peruano-chilenas. Allí está el esfuerzo integracionista del canciller José Antonio Barrenechea y del plenipotenciario Marcial Martínez en 1867. Cabe, asimismo, mencionar, despnés 
de la guerra del Pacífico y dentro de las circunstancias por ella creadas, el memorándum de José Mariano Jiménez, ministro del presidente Remigio Morales Bermúdez (19 de agosto de 1893). El mismo espíritu animó al estadista chileno Javier Vial Solar en su libro El Problema del Norte (Santiago. 1898). Sostuvo Vial Solar que chile debía ser amigo del Perú por motivos de decoro, dignidad, honradez y también en nombre de razones prácticas. Agrego que era posible superar la tesis muy frecuentemente repetida sobre una rivalidad histórica permanente e ineluctable entre los dos países y destacar y alimentar los elementos complementarios o unitivos entre ellos para buscar en el mercado de los productos y en la reciprocidad de intereses los fundamentos para un futuro más limpio.

La visión audaz y prematura que tuvieron Barrenechea, Martínez (1867), Jiménez, Vial Solar y otros (y que, en la época contemporánea, reaparece, a pesar de todo y a su manera, en Conrado Ríos Gallardo) resulta, a la luz de los días actuales, en cierta forma, coincidente con la de quienes, irguiéndose sobre océanos de sangre y de encono seculares, han forjado la buena amistas entre Francia y Alemania y han creado algo jamás visto en la historia: la Comunidad Europea. Pero que la luminosidad de los ejemplos foráneos no nos ciegue. América Latina vive hoy mucho más atrasada sicológicamente que el llamado Viejo Continente. La Comunidad Europea no oculta la prepotencia, disimulada o encubierta, de un estado en relación con otro estado, sus acuerdos no llevan en sí rezagos triunfalistas ni implican ventajas unilaterales en su realidad auténtica y en sus proyecciones futuras.

No obstante el llamado a la prudencia que las consideraciones anteriores implican, me permito recordar que debería avanzar un tipo de conversaciones bilaterales peruano-chilenas destinadas al incremento del comercio y, en general, al incremento de intereses comunes entre ambos países, sin contenido ideo político. He pensado y pienso en la conveniencia de estimular el intercambio entre Tacna y Arica, sin que él implique perjuicios para nosotros.

\section{La esperanza en un futuro más propicio}

Si fracasan las propuestas razonables para un arreglo que tome en cuenta los intereses de todos, nada empuja a la generación presente a comprometerse a resolver ahora mismo un complejo problema que va a tener una centuria y que vemos emerger nuevamente en el escenario de estos perturbados años. Quizás otra generación posterior en una época menos contaminada política y socialmente halle soluciones mutuas y razonables al amparo de una clima nuevo en el tres países, en América Latina, y en toda la comunidad internacional. Pensamos también en el potencial enorme del Perú en los tiempos que viene, a corto, mediano o largo plazo.

\section{¿Estuvo en la mente de los autores del tratado de 1929 la eventual salida al mar de Bolivia por Arica?}

Cabe suponer quizá que, eventualmente, estuvo en el ánimo de los autores del tratado peruanochileno de 1929 que, Bolivia podría tener una salida al mar por Arica. Todo el que conozco la verdadera historia de aquel pacto, suscrito por los señores Figueroa Larraín y Rada y Gamio, sabe que el verdadero cerebro que lo gestó fue el de Conrado Ríos Gallardo, Ministro de Relaciones Exteriores de Chile en aquella época.

¿Qué ha dicho este personaje a lo largo de los años? Allí está su libro anterior al arreglo entre los dos grandes adversarios de 1879: Después de la paz. Las relaciones Chileno-Bolivianos (Santiago, 1926). Allí están sus testimonios posteriores: Chile y Perú. Los Pactos de 1929. (Santiago, 1956); y Chile y Bolivia definen sus fronteras 1842 - 1904 (Santiago, 1963).

Por razones de brevedad, quiero referirme tan sólo a este último documento, cuyo epígrafe es el texto del art. $1^{\circ}$ del Protocolo Complementario de 1929, que limita la libertad de ceder a una tercera potencia el territorio de las provincias allí mencionadas.

Ríos Gallardo advierte en la "Introducción" que su objetivo es probar cómo Bolivia, "habiéndose nacido, como tantas otras naciones, sin el tributo del mar a sus pies, ambicionó salir al océano desconocido para ella y en esta pugna hubo de chocar con sus limítrofes del Pacifico" (pág.5) "Una nación separada del mar por más de ciento setenta leguas (agrega), recogida desde su origen detrás de las montañas, cuya vida se había desarrollado en le alta meseta, con habitantes que desconocían la existencia del océano, inició una disputa falaz" (pág. 6). Más adelante: "se exhibe a la luz de la estadística, la posición interior de Bolivia, su ubicación en el corazón del continente, sus necesidades reales no literarias con el mar; se expone su mediterraneidad como consecuencia directa de esta posición la cual para salvarla requiere de la cooperación de todos sus vecinos, por cuanto cada uno de ellos tiene su zona limítrofe independiente... es por todo ello que Bolivia tiene el raro privilegio de ser país del Pacífico, del Atlántico, del Amazonas, del Plata y del Paraguay" (pág. 11 y 12).

En el mismo libro, Ríos Gallardo dedica una sección del capítulo IV, relacionada con lo ocurrido en 1879, a contestar negativamente esta pregunta: ¿Tenía Bolivia lazos políticos, económicos y sociales junto al mar? (págs. $107-120$ ).

Más adelante, narra cómo, hasta la época del 


\section{La Vida y la Histaria}

Quiroz, E. El Corredor Boliviano por Arica

gobierno del almirante Montt en 1895, Chile llegó a pensar en que era dable negociar un arreglo con Bolivia condicionado a la entrega de Tacna y Arica; y cómo, a partir de 1900, la situación fue totalmente diversa, "Nuestro país (afirma) ya no podría hacerlo por los extraordinarios intereses político-económicos en juego... porque Arica se hacía presente con fuerza el principio de la nacionalidad". (pág. 158). Y en las páginas finales, después de mencionar lo ocurrido en la asamblea de la Liga de las Naciones el 28 de setiembre de 1921, afirma: "Chile y Bolivia habían definido en el campo del derecho, por última vez - permítase repetir las pablaras "por última vez" (J.B.) - sus fronteras". (pág. 201).

No sorprende, pues, que Conrado Ríos Gallardo manifestara en 1950 su opinión adversa al corredor boliviano al norte de Arica cuando lo propició el Presidente Gabriel Gonzáles Videla. Llegó al extremo de decir, entre otras cosas, que por Arica se derramó sangre chilena y sangre peruana; pero no sangre boliviana.

Podrá ser errónea aquí la tesis hostil a la salida al mar para Bolivia del estadista chileno que forjó el tratado de 1929. Contra ella se ha pronunciado oficialmente el Perú. Está abierta la discusión al respecto. Pero no cabe duda que el autor principal de aquel pacto estuvo muy lejos de la intención de abrir, con el texto del protocolo adicional a dicho documento, la eventual solución a un problema cuya existencia auténtica negó rotundamente en su libro de 1963 y en otros testimonios.

\section{¿Qué Cabe proponer en vez del corredor Banzer - Pinochet?}

Lo que el Perú proponga como fórmula o fórmulas sustitutorias a la fórmula Banzer-Pinochet será, sin duda, discutido.

Como premisa de cualquier nueva actitud habría que dejar bien en claro que el Perú no es el culpable de la mediterraneidad boliviana, como ha manifestado un diario de Panamá.

He aquí algunas ideas:

1. Arica.- Opino que, en lo concerniente a Arica, debe el Perú tomar decisiones en relación con los siguientes puntos:

1.1. La estación.- Construir una gran estación terminal para el ferrocarril entre dicho puerto y Tacna, un edifico modelo con todos los servicios que sean a él anexos para destruir, lo más pronto posible, lo que existe ahora.

1.2. El muelle.- Examinar nuevamente, con el aporte de los mejores especialistas nacionales, a cuyo lado deben estar funcionarios con visión internacional, e problema del muelle establecido por el tratado de
1929 y el de su relación con el conjunto de la bahía.

1.3. El Morro.- Pedir que salgan del Morro el museo en homenaje al Regimiento № 4 que capturó la cima el 7 de junio de 1880, y el monumento al Soldado Desconocido que recientemente se erigió en esa área. $\mathrm{Si}$ bien han sido atenuadas las muestras anti-peruanas exhibidas en el museo en la época de su apertura ( 7 de junio de 1973, gobernando Allende), no por ello deja de ser un contraste con el espíritu del tratado de 1929.

También deben desaparecer las pinturas recientes colocadas en las faldas del Morro, que representan "corvos". Muchos peruanos de hoy han olvidado que estos cuchillos o puñales de los "rotos" chilenos fueron utilizados para el repase de heridos y prisioneros. La batalla de Arica fue un choque entre infanterías.

\subsection{El "status" del puerto.- Lanzar la} iniciativa para dar un nuevo "status" al puerto dejando constancia del "desiderátum" de internacionalizarlo. Por lo menos, cabría proponer específicamente que se dé cabida amplia en la zona portuaria a los derechos $\mathrm{e}$ intereses de Chile, Bolivia y Perú.

Dentro de la finalidad de concretar este objetivo, deberían sugerirse la conveniencia de celebrar conversaciones tripartitas. Resulta obvia la peligrosidad de ellas si versan única y exclusivamente sobre el corredor.

2. Hacia un ensayo de implantación del novísimo Derecho de Integración en el cono sur del Pacífico americano.- Al mismo tiempo, el Perú podría tomar la iniciativa para la convocatoria de una reunión de expertos de los tres países aquí tantas veces mencionados, junto con emisarios de organismos internacionales, para estudiar planes concretos que explícitamente superen los tradicionales acuerdos de comercio y de cooperación técnica y económica, y se orienten a estudiar fórmulas que convierta en u hecho el modernísimo Derecho de Integración. Aquí se establecerían desde sus bases mismas, al margen del Pacto Andino hoy en crisis, relaciones prácticas entre el sur del Perú, al norte e Chile y todas las zonas de Bolivia con ellos vinculadas en un nivel administrativo y económico dentro del que tendrían cabida uniones aduaneras, autonomías portuarios, cooperación regional en proyectos de irrigación y energía, acuerdos para el desarrollo agrícola, minero e industrial, creación de "polos de desarrollo". En relación con estos últimos. conviene señalar que no deberán quedar limitados a otorgar beneficios exclusivos a Arica sino tener una gravitación regional. Toda esta nueva política audazmente planteada sin desmedro de su realismo y que podía funcionar con un sentido gradualista, estaría de acuerdo con los requisitos del proceso de una verdadera integración cuya característica esencial, en armonía con los más 
recientes especialistas en la materia, se basa en un "un grado significativo de interdependencia entre sus componentes para que un cambio ocurrido en uno produzca un cambio saludable previsible en el otro". El objetivo fundamental sería la ayuda o promoción de los pueblos de la zona de la gente.

El Perú ofrecería a Bolivia en sus puertos del Sur iguales o mayores facilidades en relación con las que existen en Rotterdam y otros centros europeos. Dejaría constancia de que ello no implica actitudes de superior a inferior sino de equivalencia e igualdad. Urge ofrecer también ventajas en la prolongación del ferrocarril Ilo-Cuajone que debe terminar en territorio boliviano con beneficio para la carga pesada. Nada de lo anterior estaría acompañado por trueques de territorios o por exigencias económicas. Un rechazo inmediato de tales propuestas u otras análogas no debería ser motivo para el desánimo. Las relaciones entre los pueblos a menudo siguen sus propios caminos distintos de los que sean señalados por las conveniencias y las facilidades al margen de lo que decreta el "país oficial", es decir "el país legal".

\section{La necesaria previsión ante el eventual mantenimiento de la situación fronteriza actual}

Conviene adelantarnos desde ahora a prever cual sería la situación en el caso de que vengan, por un motivo $\mathrm{u}$ otro, tarde o temprano, fuertes tensiones o "frotamientos" que impliquen tal vez, en alguna forma, una vuelta al estado de cosas o comienzos de agosto de 1975. Ante tan importante eventualidad, es necesario mirar con máxima atención el panorama internacional mundial y el panorama internacional regional.

\section{El gran panorama internacional y nuestro propio panorama internacional. Lo que significa la "disuasión". La necesidad de no ser "peones de ajedrez"}

En el libro de Raymond Aron antes citado que es la primera "Summa" de la política internacional contemporánea que se ha escrito, están señaladas las características de las relaciones entre los "grandes", las dos súper-potencias antagónicas, EE.UU y la URSS, y sus respectivos aliados o satélites que en alguna forma, dialécticamente, son como "hermanos enemigos" jugando el peligroso juego del conflicto y del apaciguamiento. Para el gran pensador francés, la estrategia de Occidente hoy por hoy, ante el crecimiento rápido del mundo comunista, es tratar de evitar la guerra total e ir a la coexistencia defensiva con la esperanza de que las postergaciones de la confrontación directa se prolonguen. Habría así una especie de equilibro entre los llamados "duopolos". En otras palabras, para Occidente sobrevivir implica vencer.

En lo que atañe a la URSS, desde hace algún tiempo ha sido reconocida la realidad de la coexistencia pacífica. El nuevo planteamiento surge como consecuencia del desarrollo inmenso de los nuevos medios de destrucción masiva que harían de la guerra termonuclear una amenaza segura para la humanidad. Se trata de un secreto a voces. Algo más: he aquí un fenómeno incentivado sin cesar en espiral por una tremenda dinámica. Fenómeno tan velozmente cambiante que los libros acerca a él muy pronto resultan anticuados. Así por ejemplo, el de Robin Clarke, La course á la mort ou la techonocratie de la guerre (París E. du Seuil, 1972) cuyas cuatrocientas páginas procuran infundir pavor al efectuar una descripción detallada del fantástico arsenal de los medios de destrucción surgidos desde los comienzos de la "guerra fría" tanto en la tierra, en el espacio cercano y lejano, como en la superficie y en la profundidad de los océanos. R. Clarke está abundantemente informado sobre la tecnología bélica contemporánea y sabe vulgarizar, en grado sumo, los datos minuciosos, que se relacionan con sus problemas. Pero tenemos el más legítimo derecho a suponer que ya no está a la altura de la realidad presente, todavía más gigantesca, de los "complejos militares-industriales"; y que, dentro de poco tiempo, resultará inservible.

En el XXV Congreso del Partido Comunista de la URSS celebrado en febrero de 1976, los dirigentes soviéticos hicieron el anuncio de que la distención para aseguramiento de la paz mundial es compatible con el apoyo prestado al "movimiento revolucionario democrático anti-imperialista" que está adquiriendo "proporciones cada vez más grandes". Brezhnev, ante la honda crisis estructural del capitalismo, llamó a este sistema "sociedad sin futuro". El "progresivo proceso revolucionario mundial" incide no sólo sobre países del Oeste industrializado sino, con mayor intensidad, en puntos débiles de la periferia occidental y del Tercer Mundo (Brois Meissner, "Foreing Politics at the 25th. Congress of the CPSU" en Aussen Politik, Revista de Asuntos Exteriores Alemanes, Hamburgo, Vol. 27, $\mathrm{N}^{\circ}$ 2, segundo cuatrimestre de 1976.

La más notoria expresión de amplitud en la ofensiva posición de los soviéticos está representada por la abierta injerencia en una nueva zona de conflictos regionales en África Occidental mediante su intervención en Angola donde, por vez primera dese la guerra de Corea, aprobaron y apoyaron el envío de una liado, de tropas regulares para intervenir en una guerra librada en suelo extranjero. Dichas tropas, perfectamente armadas y entrenadas, viajaron desde Cuba. Sin duda alguna, ellas están listas para cualquier 


\section{La Vida y la Fistaria}

Quiroz, E. El Corredor Boliviano por Arica

contingencia en África del Sur.

¿A dónde quieren ir las consideraciones sintetizadas en el párrafo anterior? A decir tan solo que a estas alturas del siglo XX ya no hay conflictos o guerras locales; todas son mundiales. En américa del Sur tenemos viejos litigios con sus propias características tradicionales o novedosas. Frente a la clara actualidad de ellos, nuestros países se preparan. Por lo menos, la finalidad es la de no resultar sorprendidos en la importancia del desarme. Sabemos, o debemos saber muy bien todos los peruanos, cuánto nos costó ella en 1879-83; y lo que pudo acarrear en nuestro oriente una situación análoga aunque menos trágica en 1932-33. Desde toda esta zona subdesarrollada del Tercer Mundo compramos y compramos elementos bélicos. Si el o los vecinos hacen lo mismos, intensificamos estos esfuerzos cualesquiera que sean los sacrificios. Hecho explicable. Más aún justificable desde el punto de vista de la seguridad nacional, ya que, hasta ahora, no aparece ninguna otra alternativa. Supongamos que aquí no se trata si no de esfuerzos para lograr la disuasión. Pero aquellos artefactos, mejorados incesantemente gracias a los progresos de la técnica, deben ser los más nuevos, es decir, los más sofisticados, lo cual equivale a los más costosos, en el posible, para calmar nuestras ansiedades y nuestras previsiones y también provecho de los agentes intermediarios en el negocio y de alguna o algunas de las superpotencias. Aquí surge una diferencia. Los gastos que ellos acarrean pueden afrontarlos los grandes, puesto que disponen de presupuestos casi ilimitados y, además porque tienen que atender a vitales intereses esparcidos en todos los continentes.

De ahí la enorme desproporción que existe entre ellos y nosotros no sólo en los esfuerzos y en los sacrificios sino también en la magnitud de las perspectivas bélicas.

En medio del universo diversificado y, a la vez, interrelacionado en que vivimos, los factores pasionales pesan o deben pesar menos y menos en las opciones decisivas de los dirigentes, cuyas maniobras en el campo de la diplomacia internacional tienden hoy a llevar en sí una voluntad realista y calculadora que busca disminuir las posibilidades del empleo de los súbitos golpes de fuerza, salvo casos anormales u otros que se mencionará enseguida. Son explicables las críticas a los dogmas de las teorías sobre filosofía de la historia según las cuales el provenir de la humanidad es racional o sea ya está escrito-; pero cabe admitir al mismo tiempo el axioma según el cual el hombre, sobre el dirigente responsable, es un ser más o menos racional que, si se equivoca, es porque no percibe que ello ocurre. Corolario de todo lo anteriores viene a ser la idea de que, más que nunca, desde la perspectiva de la coyuntura internacional actual, en ninguno de nuestros países debemos dejarnos seducir, o conducir, o arrastrar por fuerzas internacionales ajenas a nuestros propios intereses; fuerzas que acaso esperan en cambio utilizarnos exclusivamente al servicio de los intereses de ellas. No debemos ser peones en el juego de ajedrez de otros. La historia, con toda su majestad y todo su rigor, no es algo cerrado dentro de ella misma. Es una fuerza dinámica y actuante, porosa ante la peripecia mundial que inexorablemente nos circunda, cargada hoy de fenómenos absolutamente nuevos, completamente originales, abierta a un futuro de múltiples significaciones. Necesitamos esforzarnos, dentro de los límites de lo calculable, para definir con lucidez lo que es conveniente para nosotros en el "tiempo corto". No se trata de que olvidemos grandes tradiciones, bellos ideales y sagrados objetivos nacionales sino de que razonemos para que sean mantenidos limpiamente.

\section{El supremo esfuerzo para convertir, en caso necesario, una zona de cálida peligrosidad en zona "fría"}

En relación con nuestro problema del sur, creo que conviene no descuidarnos, no claudicar, no disipar una herencia creadora de deberes, no traicionar a los muertos, a las generaciones de hoy y a las generaciones del futuro por él afectadas; pero al mismo tiempo, mantener los ojos bien abiertos ante el presente y ante el porvenir y confiar en él. Estar en vigilia. Velar y meditar.

No se trata aquí de un almacenamiento de consideraciones vagas. Lo que se quiere decir, específicamente, es que debemos ser enérgicos en la defensa de nuestros derechos sin miedo al "que dirán" internacional; $\mathrm{y}$, al mismo tiempo, en lo que de nosotros dependa, no ir a un conflicto ahora. No es imposible la injerencia de agentes provocadores, de fuerzas interesadas en que nuestros hombres, nuestros recursos cuya previsora acumulación acaso nos ha salvado, todos nuestros demás elementos vitales, se sacrifiquen en beneficio de rencores o venganzas ideológicas, o de planes y aspiraciones internacionales con las que nada tenemos que ver.

Acordémonos de un viejo refrán ruso que, según algunos comentaristas, tuvo muy presente Eteki Mboumoua, Secretario General de la Organización de la Unidad Africana en la Cuarta Conferencia de las Naciones Unidas sobre Comercio y Desarrollo reciente celebrada en Nairobi. Dicho refrán dice así: "Mientras trancas la puerta principal contra el lobo, no olvides trancar la trasera contra el oso".

De otro lado, tampoco es imposible que al sur de nuestras fronteras estén en asecho "halcones" con 
viejas o nuevas ilusiones expansionistas; o reaccionarios con esperanzas de quebrar definitivamente nuestro desarrollo.

De ahí que hayamos postulado la eventualidad de que el Perú solicite, si fuera necesario o viable, o auspicie de un modo u otro, en el caso de una emergencia (si ella produjera, lo cual no es inevitable, pero si merece ser tomada en cuenta como eventualidad, aunque sea remota) la supervigilancia de Naciones Unidas y de la OEA en la zona que pueda calificarse como crítica al sur de nuestro territorio y en el norte de Chile. Conviene introducir a Nacionales unidad porque en el seno de la OEA han de haber, sin duda factores favorables o adversos a los países envueltos en este problema. La objeción de que tal injerencia sería demasiado costosa se debilita cuando queda hecha la aclaración de que no se trata de formar grandes contingentes como en el Cercano Oriente, sino de utilizar unos cuantos emisario simbólicos siempre y cuando sean activos y eficaces. El argumento en el sentido de que la zona antedicha necesitaría tener una amplitud excesiva dada la potencia de los armamentos modernos, puede ser respondido diciendo que una extensión moderada bastaría para ejercer tranquilizantes.

La creación de una zona "frígida" en un territorio que nominalmente debería estar en aptitud de ser "cálido" (para emplear palabras que algunas ciencias utilizan dentro de sus propios fines) acaso modere o limite el hambre insaciable de incrementar el armamentismo. El momento crítico indicado antes sería precisamente el oportuno para iniciar serias conversaciones en torno a la limitación o al encauzamiento de esos considerables egresos que roen como un cáncer la economía de nuestros países.

\section{Palabras finales}

La gran lección que no cabe desconocer es la necesidad de que el Perú vaya de inmediato, con hechos positivos y eficaces, otorgándole un carácter prioritario, al despegue sistemático de toda nuestra región del sur, si es necesario con recursos económicos y técnicos especiales.

Este planificado despegue no debe otorgar importancia exclusiva al comercio si no buscar solidas raíces en la agricultura, el fomento industrial y otorgar especial interés a un sano impulso en el campo de la educación y la cultura.

Requisito esencial en este esfuerzo será la búsqueda de auténticas condiciones de capacidad, moralidad y eficiencia para el mando en quienes asuman la difícil responsabilidad de ejercer los altos cargos en la vida administrativa local y regional.

\footnotetext{
Notas

'El informativo Político de Desco. $N^{\circ} 53$, febrero de 1977 dice lo siguiente:

El día 22 de febrero, La Prensa publica un despacho de la agencia Associated Press, fechado el día anterior en La Paz, en relación a la propuesta chilena para terminar con la mediterraneidad de Bolivia. El cable dice:

"Una comisión militar recomendó hace más de un año al Presidente boliviano Hugo Bónzer que rechazara la propuesta chilena de ceder a este país un corredor hasta el Océano Pacífico porque, de aceptarla, la seguridad nacional se enfrentaría "a su más grande peligro". El documento con la recomendación fue presentado al Presidente el 23 de diciembre de 1975 y se lo mantuvo en reserva hasta hoy. cuando fue parcialmente divulgado por el diario "Los Tiempos" de la ciudad de Cochabamba. La comisión, creada por instrucciones del Presidente, sostenía que el acceso marítimo que Bolivia conseguirá "será simplemente un mar que no subyugue" y que el precio que Chile exigía en cambio (compensación territorial siguicra equivalente a lo que cedería) era "inaceptable". El cstudio señalaba que el cortedor no significa ninguna clasc de pulmón para este país mediterráneo".
} 